PREPARED FOR THE U.S. DEPARTMENT OF ENERGY, UNDER CONTRACT DE-AC02-76CH03073

PPPL-3637rev

PPPL-3637rev

UC-70

\title{
Microturbulence and Flow Shear in High-performance JET ITB Plasma
}

by

R.V. Budny, R. Andre, A. Bécoulet, C. Challis, G.D. Conway, W. Dorland, D.R. Ernst, T.S. Hahm, T.C. Hender, D. McCune, G. Rewoldt, S.E. Sharapov, and contributors to the EFDA-JET Workprogramme

December 2001

Revised: February 2002

NM|

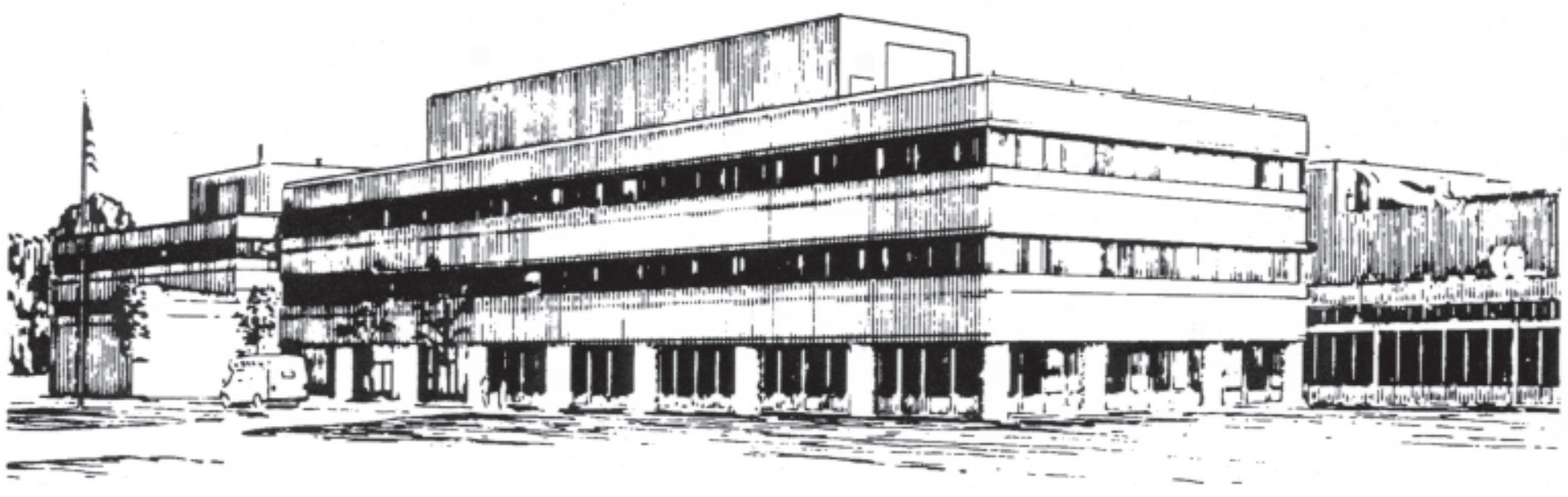

PRINCETON PLASMA PHYSICS LABORATORY PRINCETON UNIVERSITY, PRINCETON, NEW JERSEY 


\section{PPPL Reports Disclaimer}

This report was prepared as an account of work sponsored by an agency of the United States Government. Neither the United States Government nor any agency thereof, nor any of their employees, makes any warranty, express or implied, or assumes any legal liability or responsibility for the accuracy, completeness, or usefulness of any information, apparatus, product, or process disclosed, or represents that its use would not infringe privately owned rights. Reference herein to any specific commercial product, process, or service by trade name, trademark, manufacturer, or otherwise, does not necessarily constitute or imply its endorsement, recommendation, or favoring by the United States Government or any agency thereof. The views and opinions of authors expressed herein do not necessarily state or reflect those of the United States Government or any agency thereof.

\section{Availability}

This report is posted on the U.S. Department of Energy's Princeton Plasma Physics Laboratory Publications and Reports web site in Fiscal Year 2002. The home page for PPPL Reports and Publications is: http://www.pppl.gov/pub_report/

DOE and DOE Contractors can obtain copies of this report from:

U.S. Department of Energy

Office of Scientific and Technical Information

DOE Technical Information Services (DTIS)

P.O. Box 62

Oak Ridge, TN 37831

Telephone: (865) 576-8401

Fax: (865) 576-5728

Email: reports@adonis.osti.gov

This report is available to the general public from:

National Technical Information Service

U.S. Department of Commerce

5285 Port Royal Road

Springfield, VA 22161

Telephone: 1-800-553-6847 or

(703) 605-6000

Fax: (703) 321-8547

Internet: http://www.ntis.gov/ordering.htm 
revised manuscript (Feb 25, 2002) for PPCF/SFE

\title{
Microturbulence and Flow Shear in High-Performance JET ITB Plasma
}

\author{
R.V. Budny ${ }^{a *}$ R. Andre ${ }^{a}$, A. Bécoulet ${ }^{b}$, C. Challis ${ }^{c}$, G.D. Conway ${ }^{d}$, \\ W. Dorland ${ }^{e}$, D.R. Ernst ${ }^{a}$, T.S. Hahm ${ }^{a}$, T.C. Hender ${ }^{c}$, \\ D. McCune ${ }^{a}$, G. Rewoldt ${ }^{a}$, S.E. Sharapov ${ }^{c}$, \\ and contributors to the EFDA-JET workprogramme ${ }^{\dagger}$ \\ ${ }^{a}$ Princeton Plasma Physics Laboratory, P.O. Box 451, Princeton, NJ 08543, USA, \\ ${ }^{b}$ EURATOM-CEA, Cadarache, St. Paul lez Durance, France, \\ ${ }^{c}$ EURATOM/UKAEA Fusion Association, Culham Science Center, Abingdon, \\ OX14 3DB, UK, ${ }^{d}$ MPI für Plasmaphysik, EURATOM Association, Garching, Germany, \\ ${ }^{e}$ Univ. of Md., College Park, Md, USA
}

\begin{abstract}
The transport, flow shear, and linear growth rates of microturbulence are studied for a JET plasma with high central $\mathrm{q}$ in which an internal transport barrier (ITB) forms and grows to a large radius. The linear microturbulence growth rates of the fastest growing (most unstable) toroidal modes with high toroidal mode number are calculated using the GS2 and FULL gyrokinetic codes. These linear growth rates, $\gamma_{\text {lin }}$, are large, but the flow-shearing rates, $\gamma_{\mathrm{E} \times \mathrm{B}}$ (dominated by the toroidal rotation contribution) are also comparably large when and where the ITB exists.

1. Introduction - Experiments in a large number of Tokamaks have achieved reduced transport and enhanced confinement with an internal transport barrier (ITB) associated with weak or reversed magnetic shear. Key issues for extrapolating to a burning plasma regime are understanding the triggering mechanisms, formation, expansion, and sustainment of the ITB. Multiple factors may be playing roles in current experiments. Understanding these factors, such as the types of heating used, rotation, and impurities, are important for extrapolating to next step Tokamaks.
\end{abstract}

Recent experiments in JET have produced plasmas with large-radius ITB's having high neutron rates and strongly reversed magnetic shear $[1,2]$. Generally a current ramp is used with NBI, ICRH, and LHCD to prepare the plasma. The transport, flow-shearing rates $[3], \gamma_{\mathrm{E} \times \mathrm{B}}$, and linear growth rates of microturbulence are studied for one of these bestperforming plasmas with high central $q$ in which a pronounced ITB grows to large radii, with a concomitant reduction of ion thermal conductivity, $\chi_{\mathrm{i}}$ to neoclassical values, $\chi_{\mathrm{nc}}$. If a reduction in microturbulence is the cause of the reduced transport, it is plausible that either the growth rate of the microturbulence is reduced, or some mechanism such as flow shearing is preventing the microturbulence from causing large transport. We show that the linear microturbulence growth rates of the fastest growing (most unstable) toroidal mode with high toroidal mode number, $\gamma_{\text {lin }}$, are large, but $\gamma_{\mathrm{E} \times \mathrm{B}}$ are also comparably large when and where the ITB forms and expands.

A measure of the reduction in transport can be given by the ratio of $\gamma_{\mathrm{E} \times \mathrm{B}}$ and $\gamma_{\text {lin }}$, both of which are studied below. Simulations indicate that where this ratio is greater than $\simeq$

\footnotetext{
*email address: budny@princeton.edu

${ }^{\dagger}$ see appendix of J. Pamela, "Overview of recent JET results," Proceedings of IAEA Conference,
}

Sorrento, 2000 
unity, the plasma is expected to have increased confinement due to shear suppression of turbulence [4]. This effect can be summarized in:

$$
\chi_{\mathrm{i}}=\max \left\{\chi_{0}\left|1-\alpha \frac{\gamma_{\mathrm{E} \times \mathrm{B}}}{\gamma_{\text {lin }}}\right|, \chi_{n c}\right\}
$$

where $\chi_{0}$ gives the transport in the hypothetical plasma with the same conditions, but with zero $\gamma_{\mathrm{E} \times \mathrm{B}}$, and $\chi_{n c}$ is the neoclassical transport. $\chi_{0}$ is expected to be at the level of L-mode transport. The coefficient $\alpha$ is a constant of order unity. The parameterization $\alpha$ was found to vary between 0.5 and 2.0 in the nonlinear gyrofluid simulations.

In JET, neutral beam heating is required to achieve plasmas with a strong ITB in the ion temperature. The neutral injection is in the co plasma current and toroidal field direction, and generates large Mach numbers (ratio of toroidal velocity to thermal velocity), creating the large $\gamma_{\mathrm{E} \times \mathrm{B}}$. In some of these ITB plasmas the impurity densities tend to increase in the core with time. This accumulation generally occurs in JET ITB plasmas with highly peaked electron profiles. This paper shows that the flow shear and impurity contribute to decrease the micro-instability growth rate. The quasilinear particle and heat fluxes are also calculated.

There are several issues about the extrapolation of these plasmas to future tokamak reactors. It is not clear how to sustain large Mach numbers in power-producing tokamak reactors. Also a tendency for the impurities to increase in time in a reactor could extinguish the ignition. It is important to assess if these characteristics of this plasma are related to, or necessary, for the high confinement.

2. Plasma conditions - Figure 1a shows waveforms of the plasma studied. More details can be found in Ref. [2]. Modulated puffs of Neon gas were used to allow diagnosis of impurity transport properties. The line-integrated electron density and confinement enhancement $\mathrm{H}$ factors increase until a disruption terminates the plasma. The ion temperature and toroidal rotation profiles of the carbon impurity, measured by charge-exchange spectroscopy, develop a strong gradient, shown in Fig. 1b, implying the existence of several ITB's. Profiles of $n_{e}$ and $T_{e}$, shown in Ref 2, also indicate ITB's. They all appear to coincide at least for the strong ITB.

The TRANSP plasma analysis code [5] was used to analyze the discharge. Figure 2 shows the time evolutions of the ion temperature of the deuterions, $T_{i, D}$, and the ratio $\chi_{\mathrm{i}} / \chi_{\mathrm{nc}}$ at various values of the toroidal flux variable, $x \equiv \sqrt{\text { normalized toroidal flux. TRANSP }}$ calculates $T_{i, D}$ from the measured $T_{i, C}$ of carbon using local equilibration rates (described in the Appendix of Ref 5). In the center $T_{i, D}$ is lower than $T_{i, C}$ by up to $300 \mathrm{eV}$. In the following we use $T_{i}$ to denote either when the distinction is unimportant.

There are three bursts of MHD which have $n=1$ activity measured by Mirnov loops. The first, occurring around 4.4-4.6s reduces $T_{i}$ and increases $\chi_{\mathrm{i}}$. This MHD is a identified as a sawtooth-like event, associated with the transient loss of $T_{i}$ in the core, followed by a post-cursor. This sequence is similar to those often seen in JET ITB plasmas with strongly reversed magnetic shear [6]. This MHD is followed by a rapid recovery until the NBI power was ramped up around 5.0s. Around 5.2s a weak ITB forms in the plasma core. Around $5.85 \mathrm{~s}$ a strong ITB forms in the core $(x<0.4)$ and expands outward at least until $6.3 \mathrm{~s}$, where it weakens near $x=0.6$. The foot of the ITB's in $T_{i}, \omega_{t o r}, T_{e}$, and $n_{e}$ occur in approximately the same radii, and expand together [2]. Around $6.45 \mathrm{~s} T_{i}$ in the center starts to drop. The second burst of MHD is seen from 6.5 until $6.75 \mathrm{~s}$. The fast magnetics data confirms that it has $n=1$, and suggests that it has $\mathrm{m} \simeq 3$. The magnitude of the electron-cyclotron-emission fluctuations at the dominant frequency $(\approx 30 \mathrm{kHz})$ peak in the region between the two TRANSP-calculated $q=3$ surfaces. The third burst of MHD occurs around 6.84-6.9s, and is followed by a giant ELM and a fast disruption, terminating the discharge. In this paper we concentrate on the formation and expansion of the the ITB's which start around 5.2 and $5.85 \mathrm{~s}$. 
Previous experiments in JET ion heated ITB plasmas have shown localized reductions of density fluctuations in the ITB gradient region with wavelengths and frequencies in the ITG range coincident with reduced thermal diffusion [7]. The RMS density fluctuation level from the $96 \mathrm{GHz} x$-mode reflectometer channel is shown in Fig. 3. The cutoff layer position is estimated to be in the range $\mathrm{r} / \mathrm{a} \simeq 0.4-0.7$, outside the region where the ITB's first form. There is a drop in the RMS level after 5.0s till the end of the discharge. The spectra of the fluctuations are broadly spread from 20 up to $250 \mathrm{kHz}$, which when taking into account the plasma rotation velocity translates to wavelengths of a few tens of $\mathrm{cm}$ i.e. ITG range. The RMS density fluctuation level from the $75 \mathrm{GHz}$ x-mode reflectometer channel near $x=1$ does not see a RMS reduction after 5.0s. Further analysis is required for a quantitative understanding of these measurements.

Early LHCD and the plasma current ramp form a strongly reversed q profile. The measured pitch angle near the plasma axis is zero within the measurement errors, indicating a current hole with infinite $\mathrm{q}[8,9]$. The profile was measured at one time (3.8s) using MSE $[2,8]$, shown in Fig. 4. The measurement has been corrected for $E_{r}$, estimated from the measured toroidal rotation rate, but neglecting the poloidal rotation and pressure gradient. The contributions of these should be small, as shown below. The $E_{r}$ corrections to the measured pitch angle are typically 0.5-1.0 degree for these plasmas. TRANSP was used to compute the evolution at later times using the non-inductive currents and neo-classical resistivity for the Ohmic current. The value of $q_{\min }$ is slightly below 3.0 at the measurement time, and is computed to shift to lower values and shift inward. The final ITB expands into a region of positive magnetic shear, some JT-60U plasmas where the ITB tends to follow the minimum in $q[10]$.

Profiles of the total pressure are shown in Fig. 5. JET reverse shear plasmas with similarly peaked pressure profiles generally disrupt. Those with similarly peaked density profiles generally accumulate impurities. The densities of the carbon and neon impurities are measured by charge-exchange spectroscopy [11]. The density of the nickel impurity is derived from the soft X-ray emission [12]. Profiles at two times shown in Fig. 6, indicate an accumulation of impurity within the ITB region. Recently TRANSP has been upgraded to allow input of an arbitrary number of density profiles of impurity species and charge states. From these inputs, TRANSP calculates the profiles of the impurity fluxes.

The large rotation rates resulting from the co-NBI and shown in Fig. 1b imply large Mach numbers of the toroidal velocity relative to the thermal velocity. The central value of the Mach number for the carbon rises above unity around 4.0 s and nearly reaches 2.0 by the end of the discharge. The central value of the Mach number for the thermal deuterium ions is around 1.0-1.3 after 4.0s.

The flow shear rate can be calculated from the radial electric field, $E_{r}$, which can be calculated from force balance for any thermal species:

$$
\begin{gathered}
\vec{\nabla}\left(p_{i}\right)=e Z_{i}\left(\vec{E}+\vec{v}_{i} \times \vec{B}\right) \\
E_{r}=v_{T o r, i} B_{P o l}-v_{P o l, i} B_{T o r}+\frac{1}{e Z_{i} n_{i}} \nabla\left(p_{i}\right)
\end{gathered}
$$

First we calculate $E_{r}$ on the outer midplane using the measured toroidal rotation rate and the gradient of the carbon pressure, along with the poloidal rotation rate calculated from neoclassical transport using the NCLASS code [13] built into TRANSP. Examples at two times are shown in Fig. 7. The toroidal rotation term dominates $E_{r}$ even though this is a high performance plasma with a peaked pressure profile. The force balance of any of the other thermal ion species must be the same for MHD equilibrium. 
The analogous calculation for the thermal deuterium gives a similar profile for $E_{r}$ although each of the three contributions are rather different. NCLASS calculates the deuterium toroidal velocity, $v_{T o r, D}$ from the measured $v_{T o r, C}$, and and poloidal velocity, $v_{P o l, D}$ from neo-classical theory. Using these along with $T_{i, D}$ and $n_{D}$ gives the results shown in Fig. 8. The profiles of $E_{r}$ are close to those in Fig. 7, but not identical due to smoothing and errors in mapping.

The shearing rate on the outer midplane is given in terms of $E_{r}$ (Ref. [3]) by:

$$
\gamma_{\mathrm{E} \times \mathrm{B}}=\left(\frac{R^{2} B_{P o l}^{2}}{B}\right) \frac{\partial}{\partial \psi}\left(\frac{E_{r}}{R B_{P o l}}\right) \simeq\left(\frac{R B_{P o l}}{B}\right) \frac{\partial}{\partial R}\left(\frac{E_{r}}{R B_{P o l}}\right)
$$

Profiles are compared with $\gamma_{\text {lin }}$ below.

3. Micro-instability - Low frequency electrostatic drift-type instabilities, driven by ion temperature gradient (ITG), trapped-electron mode (TEM), and/or electron temperature gradient (ETG) dynamics, are candidates for the anomalous transport generally observed in Tokamak plasmas. The gyrokinetic codes GS2 and FULL were used to study this plasma. Seven species are included in the calculation: thermal electrons, thermal deuterium, the measured impurity carbon, neon, and nickel densities, the fast deuterium from the NBI, and the minority hydrogen for the ICRH.

GS2 is a comprehensive electromagnetic code $[14,15]$ for calculating the maximum growth rate $\gamma_{\max }$ and the real part of the mode frequency $\omega_{r}$ for the fastest growing mode. GS2 starts with initial-values and solves the linearized gyrokinetic equation in a general flux tube geometry. A new TRANSP postprocessor generates the GS2 inputs [16].

GS2 assumes a fixed product of the poloidal mode number $k_{\theta}(=\mathrm{nq} / \mathrm{r}$ in the circular approximation) and the ion gyro-radius $\rho_{i}$. Ranges of values for $k_{\theta} \rho_{i}$ were scanned at each time and radial zone to find $\gamma_{\max }$. Calculations were performed at $200 \mathrm{msec}$ intervals starting at $3.8 \mathrm{~s}$ and ending at $6.8 \mathrm{~s}$, and at up to 20 zones equi-spaced in $x$. Plots of the spectra at several zones when the strong ITB forms are shown in Figs. 9. At low values of $k_{\theta} \rho_{i}(<1), \gamma_{\text {lin }}$ often has a broad peak versus $k_{\theta} \rho_{i}$ with a maximum value around $k_{\theta} \rho_{i}$ $=0.30-0.50$. This range is around that typically found for gyrokinetic and gyrofluid simulations. The mode frequency $\omega_{l i n}$ is positive (in the ion diamagnetic direction), typical of the ITG branch. At larger values of $k_{\theta} \rho_{i}, \omega_{l i b}$ changes sign and the trapped electron mode (TEM) and/or the electron temperature gradient mode (ETG) branch dominate. These branches can interact non-linearly, but we have not studied that interaction.

Generally, the spectra have large peaks at large $k_{\theta} \rho_{i} \approx 40.0$. Although the amplitude is much larger than that of the ITG mode, the wavelength is too small to have a direct effect on the ions. Since this paper focuses on the ion channel, we do not address TEM or ETG contributions. In the following we denote the maximum growth rate for $k_{\theta} \rho_{i}<1.0$ as $\gamma_{I T G}$, and the value at $k_{\theta} \rho_{i}=0.40$ by $\gamma_{0.4}$. The calculated linear growth rates $\gamma_{I T G}$ remains large $(\simeq 0.2$ Mradians/s $)$ at large radii on the outer mid-plane. Examples are shown in Fig. 10.

In Figs. 11 we show the time evolution of $\gamma_{I T G}$ and $\gamma_{\mathrm{E} \times \mathrm{B}}$ at various values of $x$. Figures 11 (a-b), show that the onset of the strong transport barrier in the core $(x<0.6)$ occurs when $\gamma_{\mathrm{E} \times \mathrm{B}}>\approx \gamma_{I T G}$ consistent with the simple form of the Waltz criterion (Eq.1). However, at larger radii $(x>0.5$ in Fig. $11(\mathrm{c}-\mathrm{d}))$, we find that $\gamma_{I T G}$ exceeds $\gamma_{\mathrm{E} \times \mathrm{B}}$. The ITB appears to expand out and become weak around $x=0.55$ at $6.4 \mathrm{~s}$. The weakening of the ITB past $x=0.55$ appears to be consistent with Figs. 11 (c-d), unless $\alpha$ in Eq.(1) increased above unity at larger radii for some reason.

This JET discharge was also analyzed for three times using the comprehensive microinstability code the FULL code $[17,18]$. FULL is an eigenvalue code, whereas GS2 is an 
initial-value code, and the two codes have been bench marked in Ref. [14]. Both codes employ the "ballooning representation" for high- $n$ micro-instabilities, and include all relevant local physics associated with linear gyrokinetic theory. The full electromagnetic version of the GS2 code was used, whereas only the electrostatic version of FULL was used. For the FULL code calculations, a Maxwellian equilibrium distribution function is used for all of the species except the hot beam ions, for which a slowing-down distribution is used. The stabilizing effect of $\gamma_{\mathrm{E} \times \mathrm{B}}$ is included in the calculation using the model described in Refs. $[19,20]$. The FULL code is used to calculate linear growth rates and real frequencies, as well as quasilinear particle and energy fluxes for each species, for the electrostatic ITG and TEM modes.

Profiles at the final time studied (6.8s) are shown in Fig. 12. The FULL results are shown with three different cases of assumptions: 1) one effective impurity, but no rotation; 2) the three measured impurities, but no rotation; and 3) the three impurities with including the rotation model. The linear growth rates without rotation are shown with $k_{\theta} \rho_{i}$ held fixed at 0.47 , and the rate with rotation at $k_{\theta} \rho_{i}=0.68$. The effect of using the three impurity species instead of combining them together reduces the growth rate slightly. For instance, at $x=0.5$, the values of $\gamma_{\text {lin }}$ would be 0.210 [Mradians $/ \mathrm{s}$ ] if impurities were omitted, 0.184 using one average impurity, 0.199 with only the carbon, 0.195 with the addition of neon, and 0.134 with the addition of nickel. Thus at this time and radius the no impurity result is reduced about $36 \%$ by inclusion of the measured impurities. The inclusion of rotation in the FULL analysis is seen to strongly suppress the linear growth rate, with positive values only near the plasma edge $(x>0.7)$, consistent with the radial extent of the strong ITB. FULL indicates that this mode is unstable over most of the plasma cross section at all three times examined $(4.8,5.8$ and $6.8 \mathrm{~s})$ if rotation is not included, but the unstable region at each time becomes much narrower when rotation is included.

Figure 12 also shows the GS2 results for comparison. Since the GS2 results for $\gamma_{\text {lin }}$ do not vary significantly between $k_{\theta} \rho_{i}=0.40$ and 0.47 , the one-impurity, no-rotation FULL profile and the GS2 $\gamma_{0.4}$ profile should be very similar (according to the benchmarking of the two codes) except that 1) different sources for the MHD equilibria were used, 2) different smoothing of the data was used, 3) The modes were held fixed for the FULL scans, but are maximized at each radius for the GS2 scans, and 4) the electromagnetic contributions were included in the GS2 calculation.

The quasilinear heat and particle fluxes are calculated by both the GS2 and FULL codes. The unknown nonlinear saturation level for the instability determines the absolute level of each individual flux, but divides out for the ratios of fluxes. FULL indicates that the ratio $Q_{\text {thermal-ion }} / Q_{e} \equiv\left(Q_{D}+Q_{C}+Q_{N e}+Q_{N i}\right) / Q_{e}$ is much larger than unity in the unstable regions with rotation for $t=4.8$ and $5.8 \mathrm{~s}$, but becomes smaller than unity for $t=6.8 \mathrm{~s}$. A trend in the same direction is seen for the corresponding experimental flux ratios computed by TRANSP. The quasilinear particle fluxes of the $\mathrm{C}, \mathrm{Ne}$, and $\mathrm{Ni}$ flow inward in the regions of positive $\gamma_{\text {lin }}$ at 4.8 and $5.8 \mathrm{~s}$. At $6.8 \mathrm{~s}$, the $\mathrm{C}$ and Ne fluxes are outward whereas the Ne flux remains inward. These trends are in qualitative agreement with the accumulation of impurity in JET ITB plasmas [11,12]. It will be interesting to compare these quasilinear fluxes with impurity transport measurements in JET.

4. Discussion - The expansion of the ITB outward from the core, in particular its apparent deviation from the radial evolution of the $q_{\min }$ surface, deserves further studies and understanding. This paper shows that the GS2 comparison of $\gamma_{I T G}$ with $\gamma_{\mathrm{E} \times \mathrm{B}}$ in Figs. 10-11 are consistent with the Waltz criterion (Eq.1). The FULL results without rotation are in approximate agreement with the GS2 results. The FULL results with the self-consistent inclusion of rotation are also in approximate agreement with the formation and expansion of the ITB out to $x \approx 0.6$.

One should note that in the model for $\chi_{\mathrm{i}}$ in Eq. (1), $\gamma_{\text {lin }}$ may be oversimplified for several reasons. Dimits [21] showed that $\chi_{i}$ vs. shearing rate is often not a linear function, and 
also points out, as have others, that sheared parallel flow (which has been neglected in these gyrokinetic calculations) can have a destabilizing effect that partially offsets the stabilizing influence of sheared ExB perpendicular flows. More accurate models of the effects of sheared flows, and fully nonlinear calculations of their effects for comparison with particular experiments, would be interesting work for the future.

The reduction of ion transport correlates with increases of $\gamma_{\mathrm{E} \times \mathrm{B}} / \gamma_{I T G}$. A similar correlation of ion transport with $\gamma_{\mathrm{E} \times \mathrm{B}} / \gamma_{I T G}$ has been found for ELMy H-mode plasmas in JET [22]. Generally the linear growth rate appears to decrease slightly, but remains large in the presence of the strong ITB and reduced transport. The flow shearing rate tends to increase when and where the strong ITB exists. It is dominated by the large measured toroidal rotation velocity resulting from the co-injection of the NBI. In stronglyrotating JET plasmas the measured pressure gradient does not contribute significantly to the radial electric field and to the calculated flow shearing rate. In other Tokamaks, such as TFTR with both co and counter aimed NBI, strong ITB's could be produced even with balanced NBI as a consequence of the significant role of the pressure gradient. The toroidally-driven flow shear in JET ITB plasmas offer the potential for even higher performance in JET. However, if the pressure gradient term remains insignificant for future large Tokamaks, an externally driven flow shear may be required to stabilize the microturbulence.

5. Acknowledgments - This work has been conducted under the European Fusion Development Agreement and supported in part by the US DoE Contract No. DE-ACO2$76 \mathrm{CHO} 3073$. 


\section{Bibliography}

[1] A. Bécoulet, et al., "Overview of Internal Transport Barrier Studies on EFDA-JET", to be published

[2] C. Challis, Yu Baranov, A. Bécoulet, N.C. Hawkes, et al., "High Fusion Performance in JET Plasma ..", submitted for publication in PPCF/SFE.

[3] T.S. Hahm and K.H. Burrell, Phys. Plasmas 2, 1648 (1995).

4 R.E. Waltz, G.D. Kerbel, and J. Milovich, Phys. Plasmas 1, 2229 (1994).

5 R.V. Budny, M.A. Bell, H. Biglari, A. Janos, et al., Nucl. Fusion 35, 1497 (1995).

6 T.C. Hender, et al., submitted to PPCF/SFE

7. G.D. Conway, D. Borba, B. Alper, et al. (2000) Phys. Rev. Lett. 841463.

8] N. Hawkes, et al., submitted to PPCF; [9] N. Hawkes, et al., Phys. Rev. Lett. 87 115001-1 (2001);

[10] T. Fujita, et al., Nucl. Fusion 38, 207 (1998).

11] C. Giroud, K.-D. Zastrow, P. Andrew, R. Dux, et al., 28th EPS, Madeira, 2001, P2.018

[12] R. Dux, C. Ingesson, C. Giroud, K.-D. Zastrow, et al., 28th EPS, Madeira, 2001, P2.007

[13] W.A. Houlberg, K.C. Shang, S.P. Hirshman, and M.C. Zarnstorff, Phys. of Plasmas 4, 3230 (1997).

[14] M. Kotschenreuther, G. Rewoldt, W.M. Tang, Comp. Phys. Comm. 88, 128 (1995).

15 W. Dorland, B.N. Rogers, F. Jenko, et al., IAEA-CN-77/TH2/5, presented at the Eighteenth International Conference on Fusion Energy, Sorrento, Italy, 4-10 October 2000 .

[16] D. Ernst,, R.E. Bell, M.G. Bell, R.V. Budny, et al., Phys. of Plasmas 7, 615 (2000)

17 G. Rewoldt, W.M. Tang, M.S. Chance, Phys. Fluids 25 (1982) 480.

18 G. Rewoldt, W.M. Tang, R.J. Hastie, Phys. Fluids 30 (1987) 807.

19] G. Rewoldt, M.A. Beer, M.S. Chance, T.S. Hahm, Z. Lin, W.M. Tang, Phys. Plasmas 5 (1998) 1815.

[20] G. Rewoldt, M.S. Chance, T.S. Hahm. W.M. Tang, in Proceedings of the 1998 International Conference on Plasma Physics combined with the 25th European Physical Society Conference on Controlled Fusion and Plasma Physics, Praha, June 29 - July 3, 1998, Edited by Pavlo, P., Europhysics Conference Abstracts, Vol. 22C, published on CD-ROM, paper G046PR (P1.195). This paper is available on the web in PDF format at: http://epsppd.epfl.ch/Praha/WEB/AUTHOR_R.HTM

[21] A. Dimits, Dimits presented at the Eighteenth International Conference on Fusion Energy, Sorrento, Italy, 4-10 October 2000

[22] R. Budny, B. Alper, D. Borba, J.G. Cordey, et al., Nuclear Fusion 42 66, (2002) 


\section{Figure Captions}

Figure 1 - a) Waveforms of the plasma studied. The vertical dashed lines indicate approximate start times of ITB occurrences (at 5.2 and $5.85 \mathrm{~s}$ ); b) profiles of the ion temperature and toroidal rotation rate measured in the carbon impurity

Figure 2 - Time evolutions of the ion temperature and $\chi_{\mathrm{i}} / \chi_{\mathrm{nc}}$ at various values of the

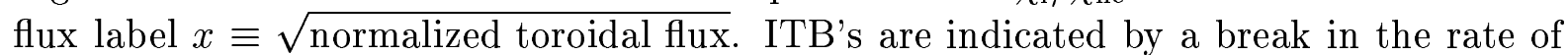
increase of $T_{i, D}$ around $5.2 \mathrm{~s}$ and $5.85 \mathrm{~s}$. Decreases in the ratio $\chi_{\mathrm{i}} / \chi_{\mathrm{nc}}$ tend to occur soon after the occurrence of the strong ITB triggered in the core at $5.85 \mathrm{~s}$.

Figure 3 - a) fluctuation level at the $96 \mathrm{GHz}$ x-mode versus time. b) the corresponding region of normalized $\mathrm{r} / \mathrm{a}$ is in the range $0.4-0.7$. The ITB's form closer to the plasma axis.

Figure 4 - Profiles of $q$ measured by MSE (corrected for $\mathrm{E}_{r}$ ) at $3.8 \mathrm{~s}$ and computed by TRANSP at later times. b) is a zoom of a).

Figure 5 - Profiles of total pressure computed by TRANSP

Figure 6 - Profiles of the $\mathrm{C}, \mathrm{Ne}$, and $\mathrm{Ni}$ impurity densities at the time of the formation of the strong, persistent ITB and just before disruption. $n_{i m p}$ is the single effective impurity density that gives the same $Z_{\text {eff }}$ as the $\mathrm{C}$, Ne, and $\mathrm{Ni}$ densities. For comparison, the electron density divided by 100 is shown.

Figure 7 - Profiles of contributions to the radial electric field along the outer midplane, calculated from force balance on carbon and mapped to $x$ at the start of the weak ITB and near the end of the plasma. Generally the carbon pressure gradient term is a small contribution to $E_{r}$ in JET, except possibly in the pedestal.

Figure 8 - Profiles of contributions to the radial electric field along the outer midplane, calculated from force balance on deuterium and mapped to $x$ at the start of the weak ITB and near the end of the plasma. The deuterium pressure gradient term is relatively large, but is partially canceled by the $\mathrm{v}_{p o l, D}^{N C}$ term. If the $\mathrm{v}_{t o r}$ term were small, $\mathrm{E}_{r}$ would be also.

Figure 9 - GS2 scan in $k_{\theta} \rho_{i}$ at $5.8 \mathrm{~s}$, just before the start of the strong, sustained ITB at $5.85 \mathrm{~s}$. a) The linear growth rate $\gamma_{\max }$ has a local ITG peak near $k_{\theta} \rho_{i} \approx 0.50$ and a large ETG peak near $k_{\theta} \rho_{i} \approx 40$. b) the mode frequency, $\omega_{\max }$ is in the positive ion-drift direction for the ITG branch, but switches sign, becoming negative (in the electron-drift direction) after $k_{\theta} \rho_{i} \approx 2.0$ Convergence of the GS2 calculations is difficult to obtain in the region around $k_{\theta} \rho_{i} \approx 1.2$ where both the ITG and TEM branches have comparable contributions.

Figure 10 - GS2 profiles of $\gamma_{0.4}$ and $\gamma_{I T G}$ compared with $\gamma_{\mathrm{E} \times \mathrm{B}} \cdot \gamma_{I T G}$ is the result for $k_{\theta} \rho_{i}<1.0$, and $\gamma_{0.4}$ is the result for $k_{\theta} \rho_{i}=0.4$. At early times the growth rates are greater than the flow shear rates. As of $5.6 \mathrm{~s}, \gamma_{\mathrm{E} \times \mathrm{B}}$ exceeds $\gamma_{I T G}$ around $\mathrm{x}=0.3$. Rectangles indicate approximate locations of the $T_{i}$ ITB.

Figure 11 - Time evolutions at various zones. The rectangles indicate approximate occurrences of the break in the rate of increase of the local $T_{i}$ indicated in Fig. 2. The ITB's are very weak if they exist at all, for $x \geq 0.6$.

Figure 12 - Profiles of FULL and GS2 results at 6.8s, when the ITB has weakened or ceased to exist by $x=0.7$. Three profiles from FULL compare the growth rate calculated assuming a) a single average impurity species with no rotation and $k_{\theta} \rho_{i}=0.47$, b) three separate impurity species $\left(\mathrm{C}, \mathrm{Ne}\right.$, and $\mathrm{Ni}$ ) with no rotation and $k_{\theta} \rho_{i}=0.47$, and c) three separate impurity species, rotation, and $k_{\theta} \rho_{i}=0.68$. The GS2 results use the three impurity species, but do not include the rotation self-consistently. $\gamma_{I T G}$ is the GS2 result for $k_{\theta} \rho_{i}<1.0$, and $\gamma_{0.4}$ is the GS2 result for $k_{\theta} \rho_{i}=0.4$. The GS2 and FULL calculations started with the same TRANSP run, but used slightly different assumptions, as described in the text. 


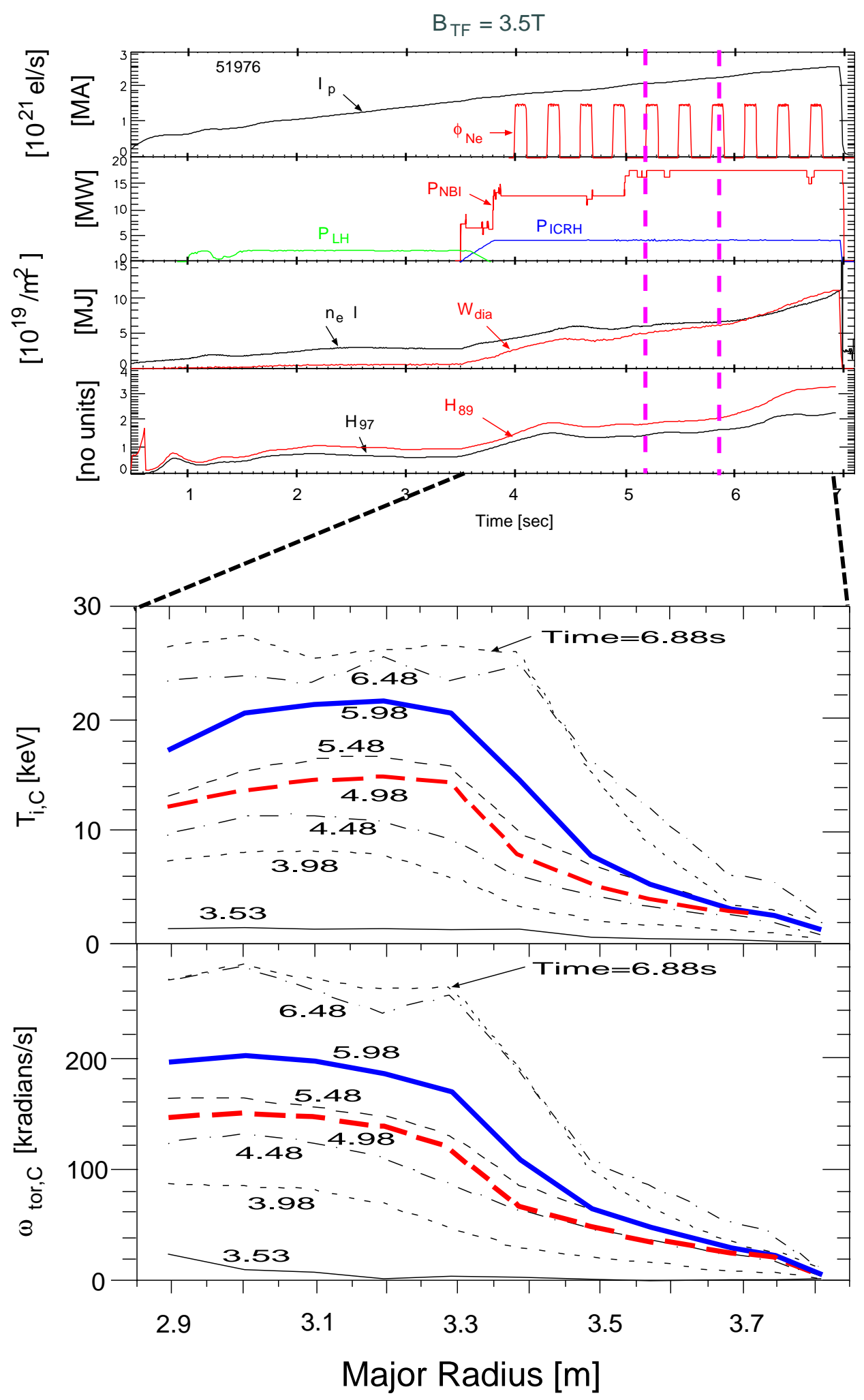

Figure 1 - a) Waveforms of the plasma studied. The vertical dashed lines indicate approximate start times of ITB occurrences (at 5.2 and $5.85 \mathrm{~s}$ ); b) profiles of the ion temperature and toroidal rotation rate measured in the carbon impurity 


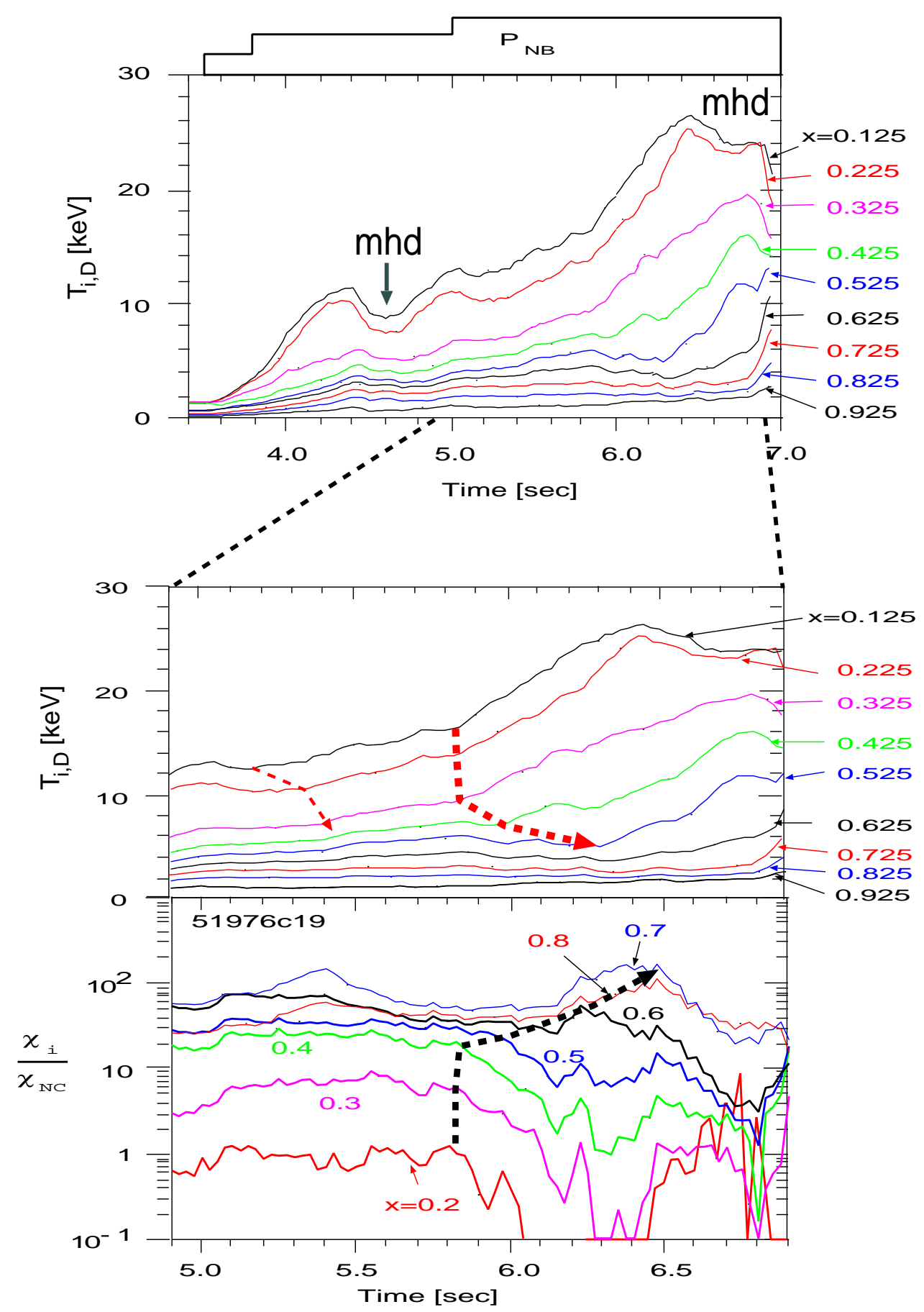

Figure 2 - Time evolutions of the ion temperature and $\chi_{\mathrm{i}} / \chi_{\mathrm{nc}}$ at various values of the flux label $x \equiv \sqrt{\text { normalized toroidal flux. }}$. ITB's are indicated by a break in the rate of increase of $T_{i, D}$ around $5.2 \mathrm{~s}$ and $5.85 \mathrm{~s}$. Decreases in the ratio $\chi_{\mathrm{i}} / \chi_{\mathrm{nc}}$ tend to occur soon after the occurrence of the strong ITB triggered in the core at $5.85 \mathrm{~s}$. 
$96 \mathrm{GHz} x$-mode

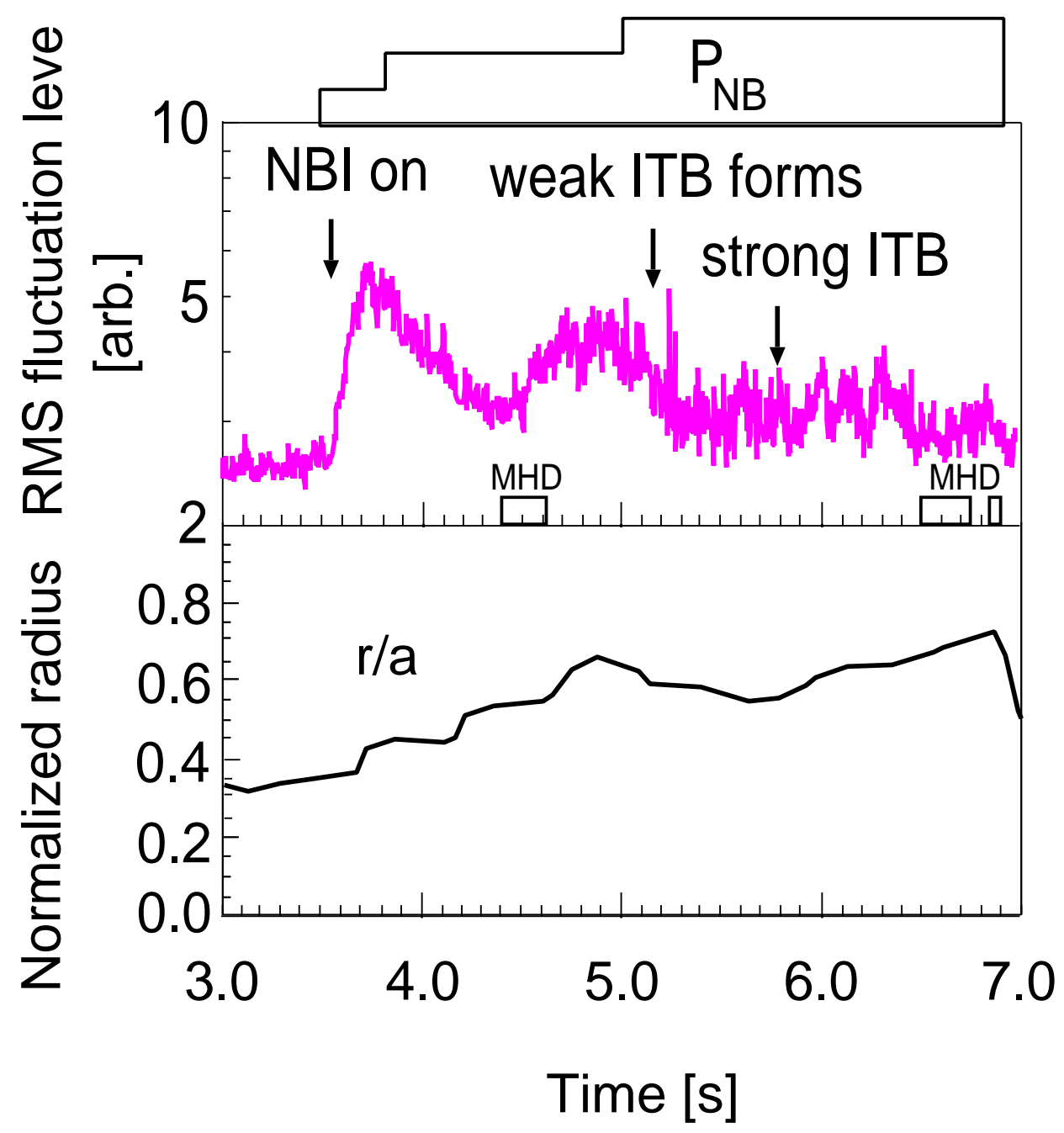

Figure 3 - a) fluctuation level at the $96 \mathrm{GHz}$ x-mode versus time. b) the corresponding region of normalized $\mathrm{r} / \mathrm{a}$ is in the range 0.4-0.7. The ITB's form closer to the plasma axis. 


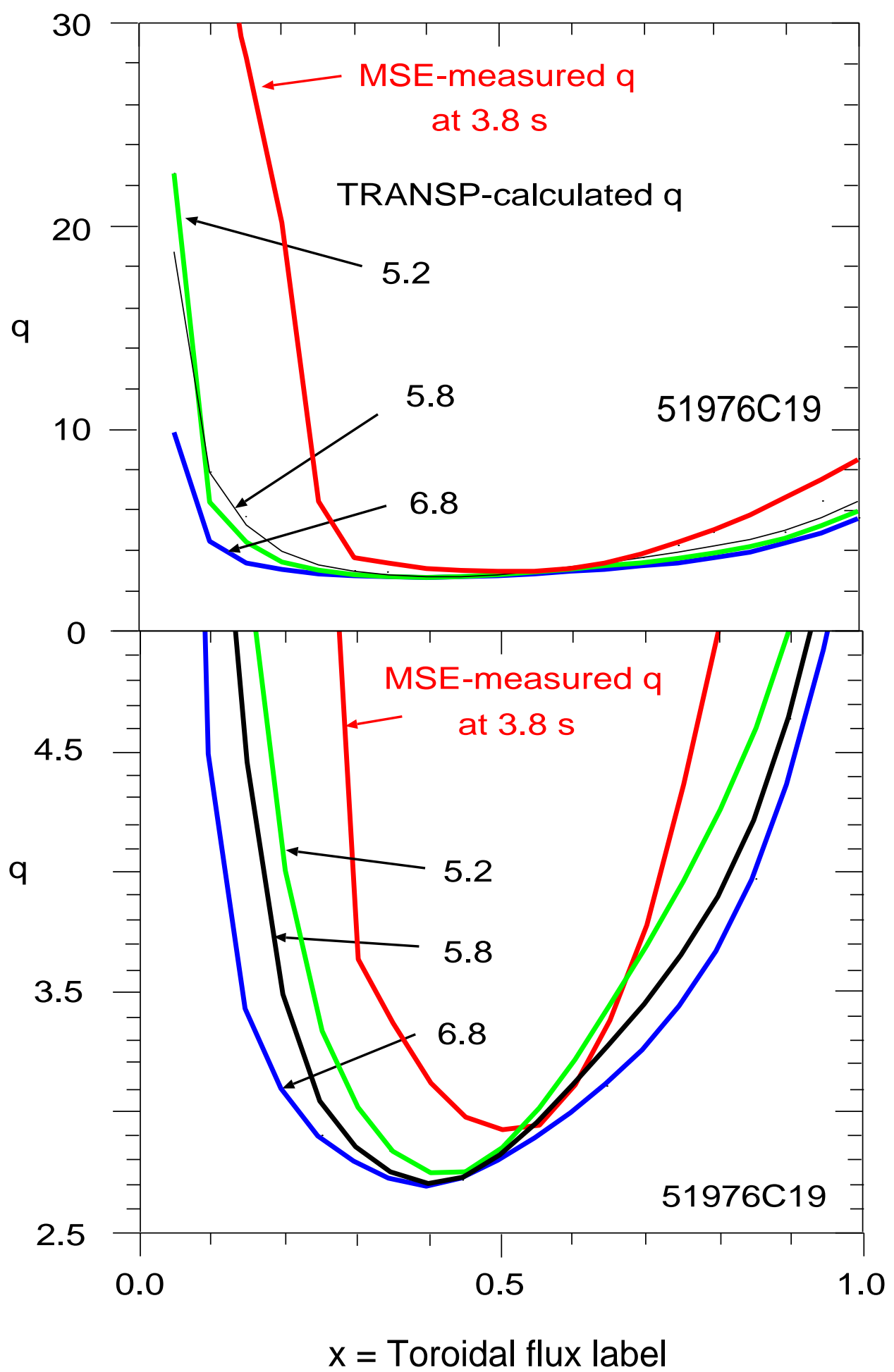

Figure 4 - Profiles of $q$ measured by MSE (corrected for $\mathrm{E}_{r}$ ) at $3.8 \mathrm{~s}$ and computed by TRANSP at later times. b) is a zoom of a). 


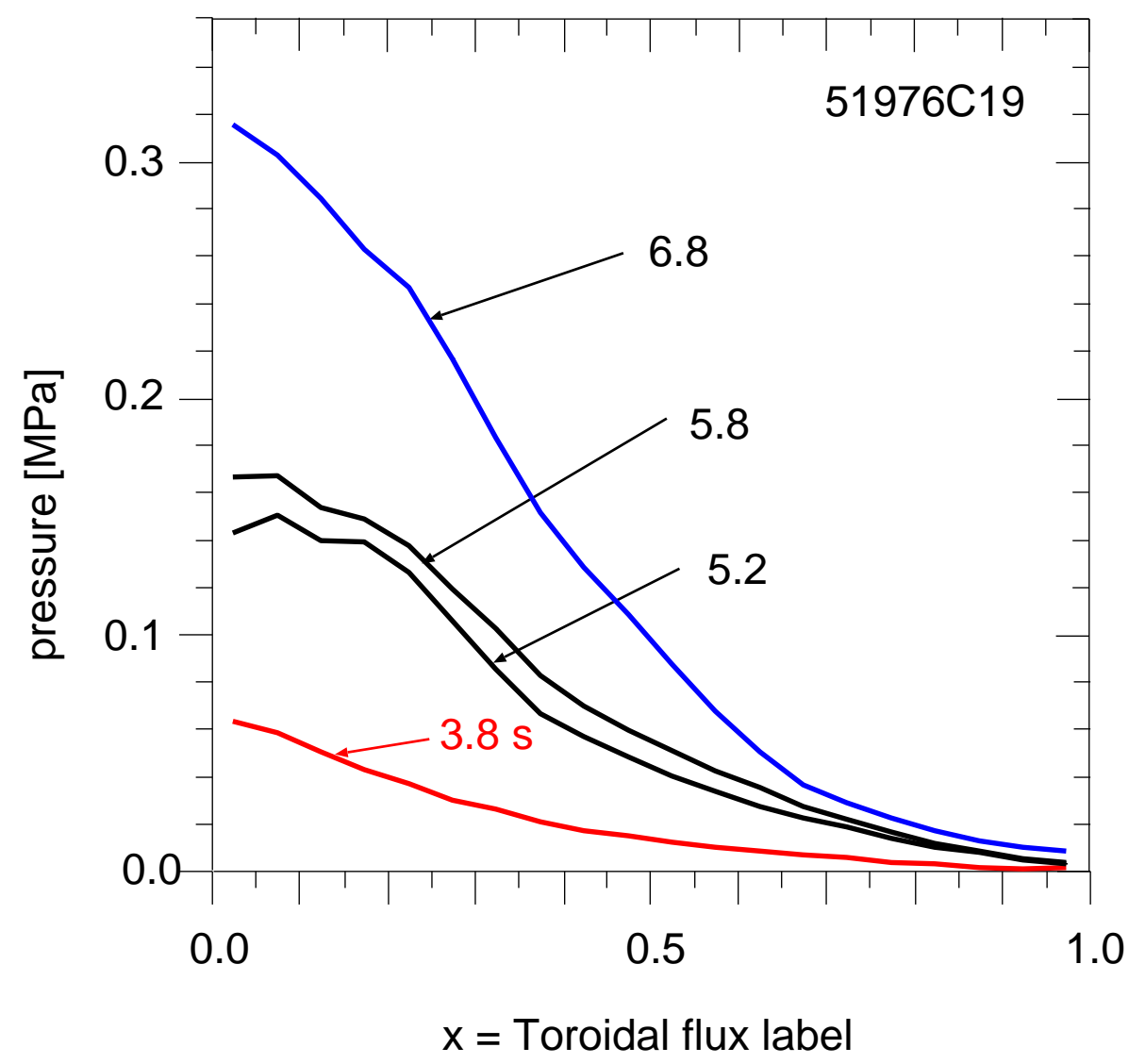

Figure 5 - Profiles of total pressure computed by TRANSP 


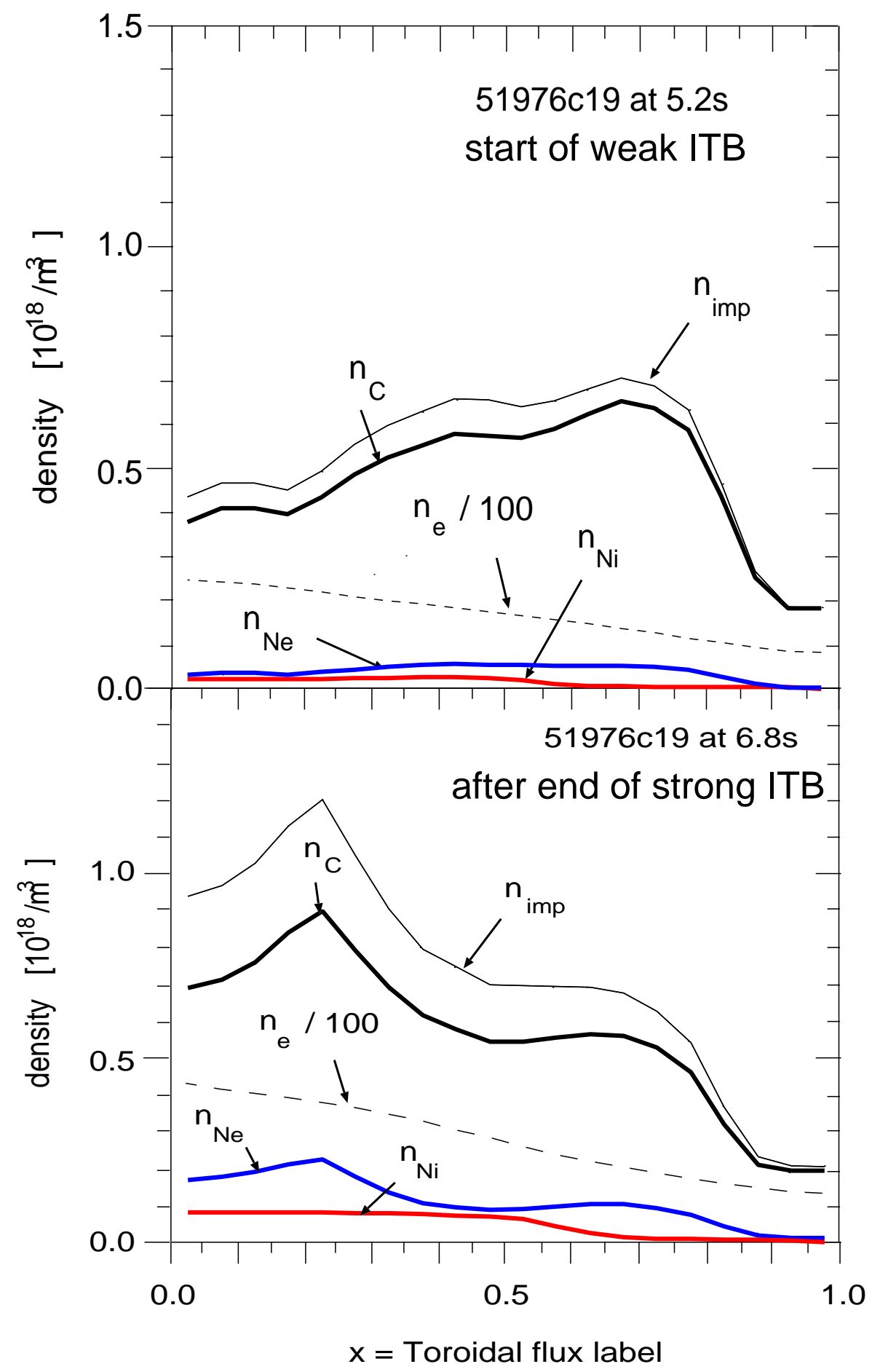

Figure 6 - Profiles of the $\mathrm{C}, \mathrm{Ne}$, and $\mathrm{Ni}$ impurity densities at the time of the formation of the strong, persistent ITB and just before disruption. $n_{i m p}$ is the single effective impurity density that gives the same $Z_{\text {eff }}$ as the $\mathrm{C}, \mathrm{Ne}$, and $\mathrm{Ni}$ densities. For comparison, the electron density divided by 100 is shown. 


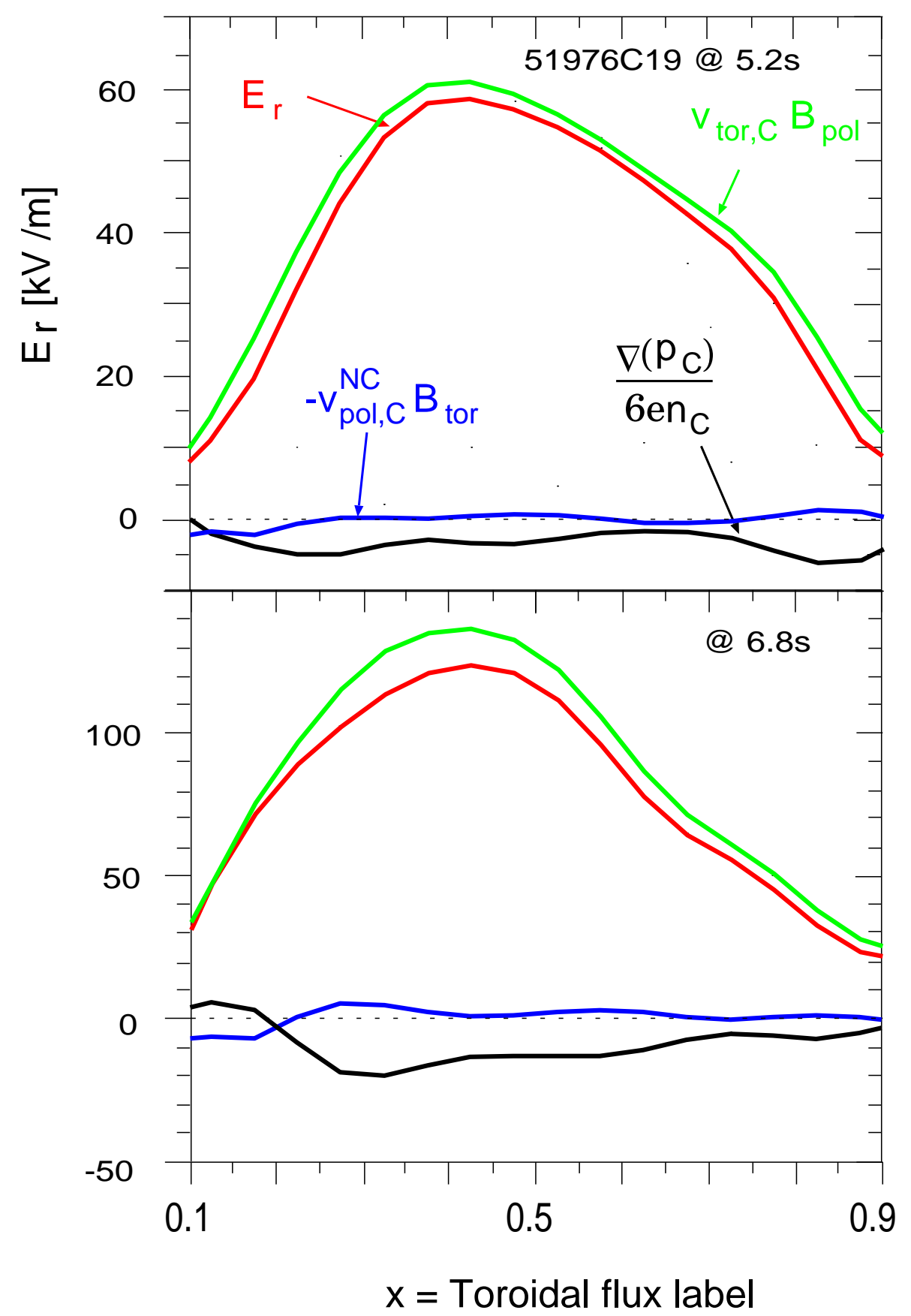

Figure 7 - Profiles of contributions to the radial electric field along the outer midplane, calculated from force balance on carbon and mapped to $x$ at the start of the weak ITB and near the end of the plasma. Generally the carbon pressure gradient term is a small contribution to $E_{r}$ in JET, except possibly in the pedestal. 


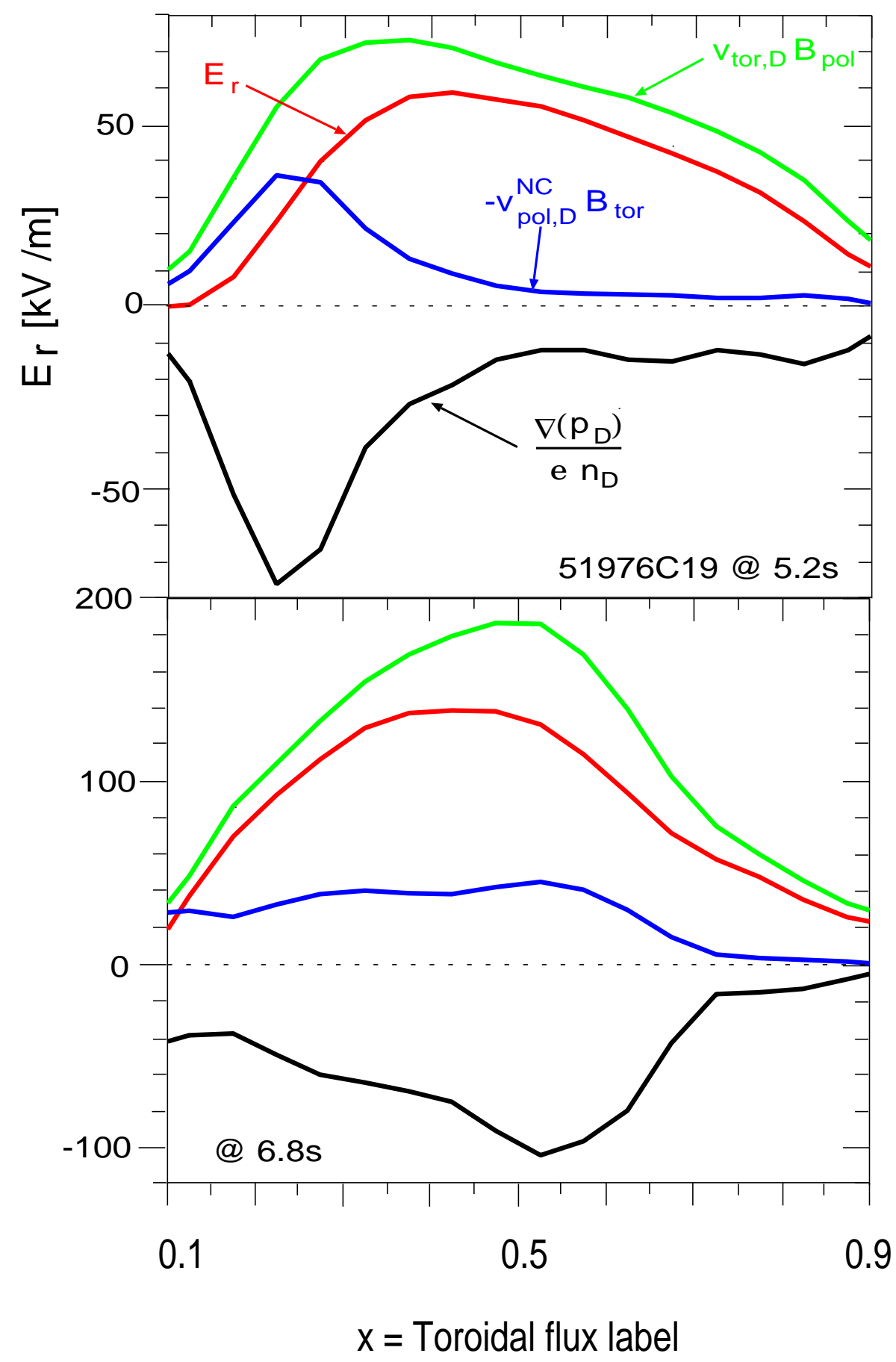

Figure 8 - Profiles of contributions to the radial electric field along the outer midplane, calculated from force balance on deuterium and mapped to $x$ at the start of the weak ITB and near the end of the plasma. The deuterium pressure gradient term is relatively large, but is partially canceled by the $\mathrm{v}_{\text {pol, }, D}^{N C}$ term. If the $\mathrm{v}_{\text {tor }}$ term were small, $\mathrm{E}_{r}$ would be also. 

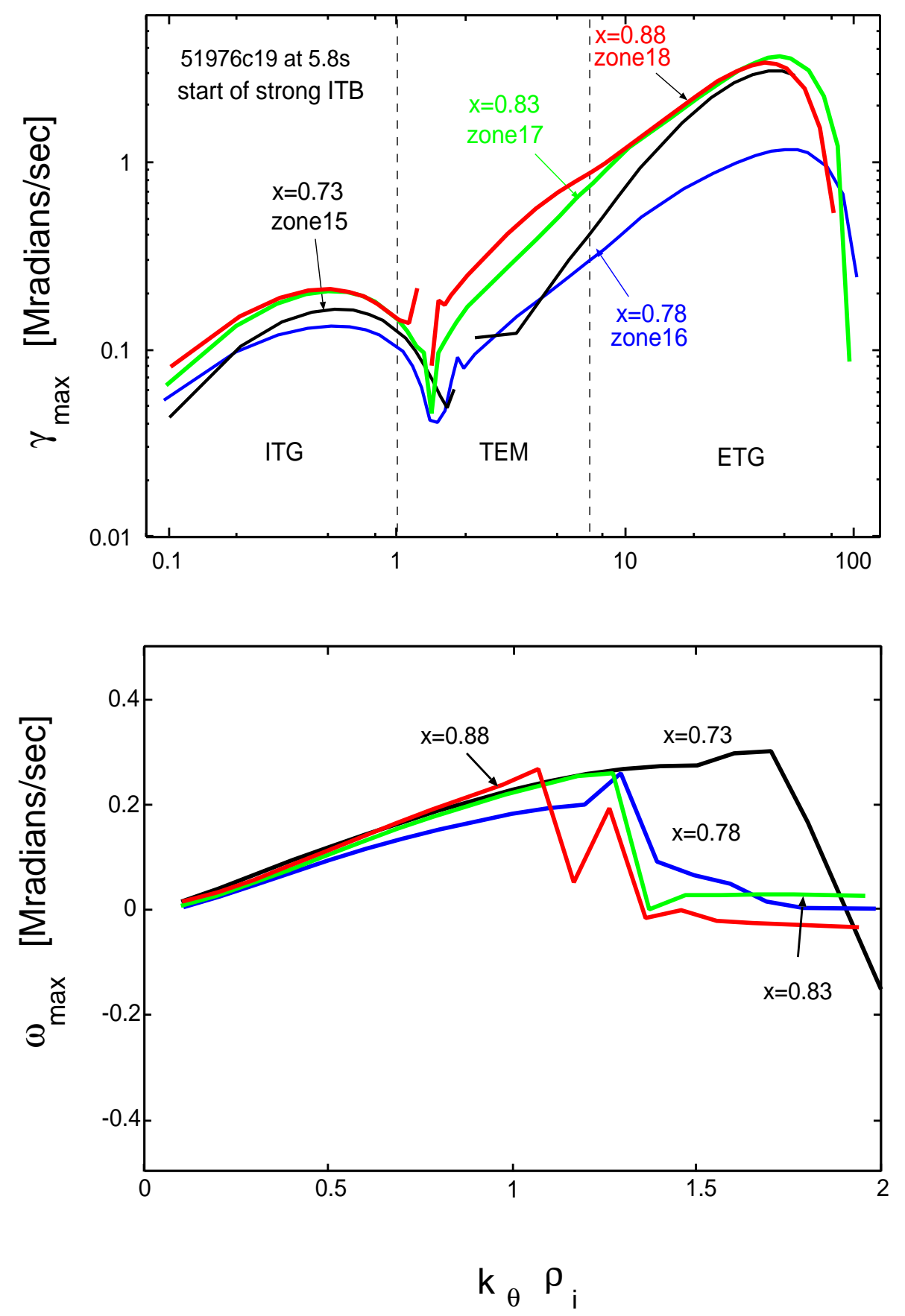

Figure 9 - GS2 scan in $k_{\theta} \rho_{i}$ at $5.8 \mathrm{~s}$, just before the start of the strong, sustained ITB at 5.85s. a) The linear growth rate $\gamma_{\max }$ has a local ITG peak near $k_{\theta} \rho_{i} \approx 0.50$ and a large ETG peak near $\left.k_{\theta} \rho_{i} \approx 40 . \mathrm{b}\right)$ the mode frequency, $\omega_{\max }$ is in the positive ion-drift direction for the ITG branch, but switches sign, becoming negative (in the electron-drift direction) after $k_{\theta} \rho_{i} \approx 2.0$ Convergence of the GS2 calculations is difficult to obtain in the region around $k_{\theta} \rho_{i} \approx 1.2$ where both the ITG and TEM branches have comparable contributions. 


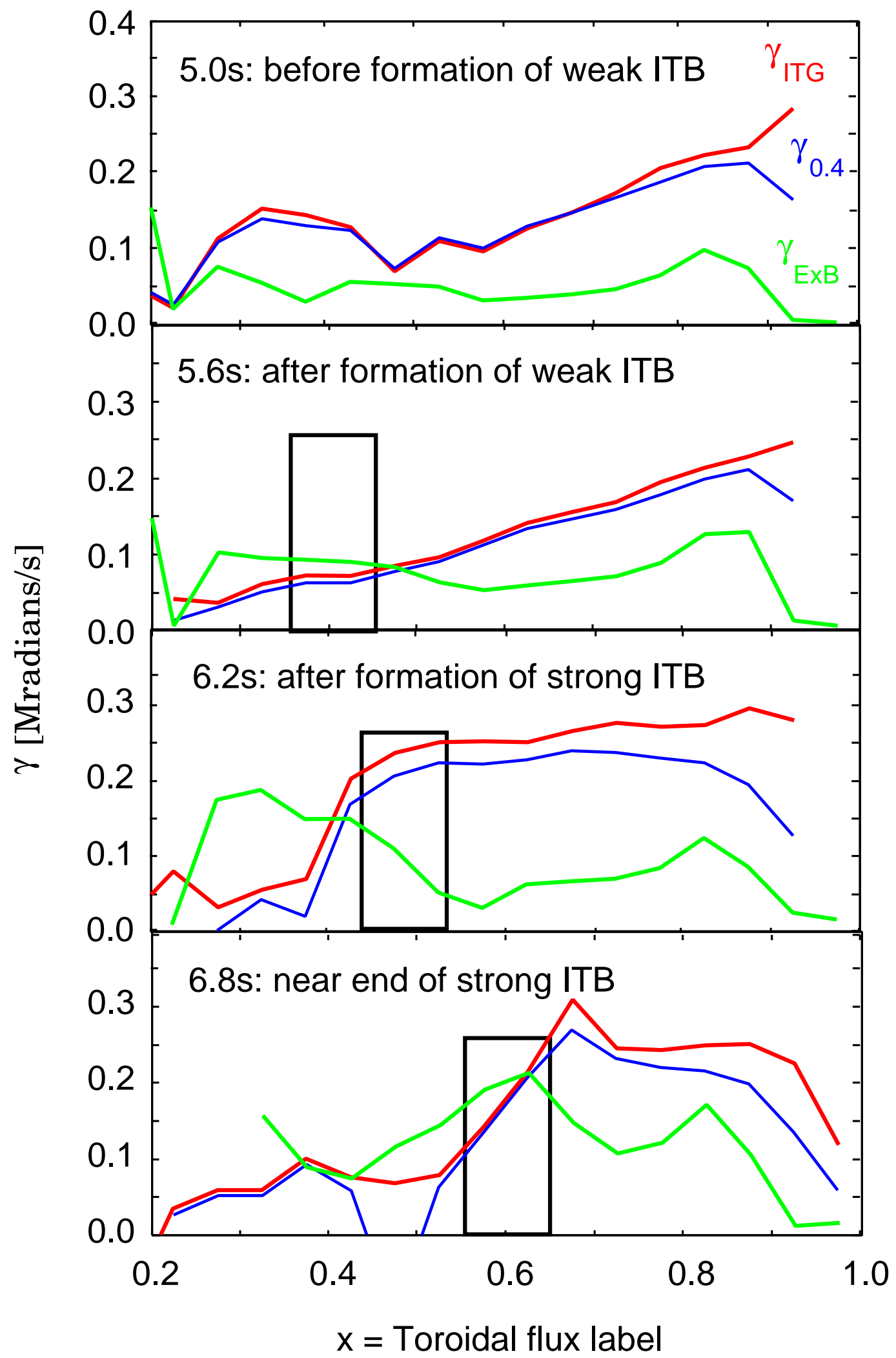

Figure 10 - GS2 profiles of $\gamma_{0.4}$ and $\gamma_{I T G}$ compared with $\gamma_{\mathrm{E} \times \mathrm{B}} \cdot \gamma_{I T G}$ is the result for $k_{\theta} \rho_{i}<1.0$, and $\gamma_{0.4}$ is the result for $k_{\theta} \rho_{i}=0.4$. At early times the growth rates are greater than the flow shear rates. As of $5.6 \mathrm{~s}, \gamma_{\mathrm{E} \times \mathrm{B}}$ exceeds $\gamma_{I T G}$ around $\mathrm{x}=0.3$. Rectangles indicate approximate locations of the $T_{i}$ ITB. 


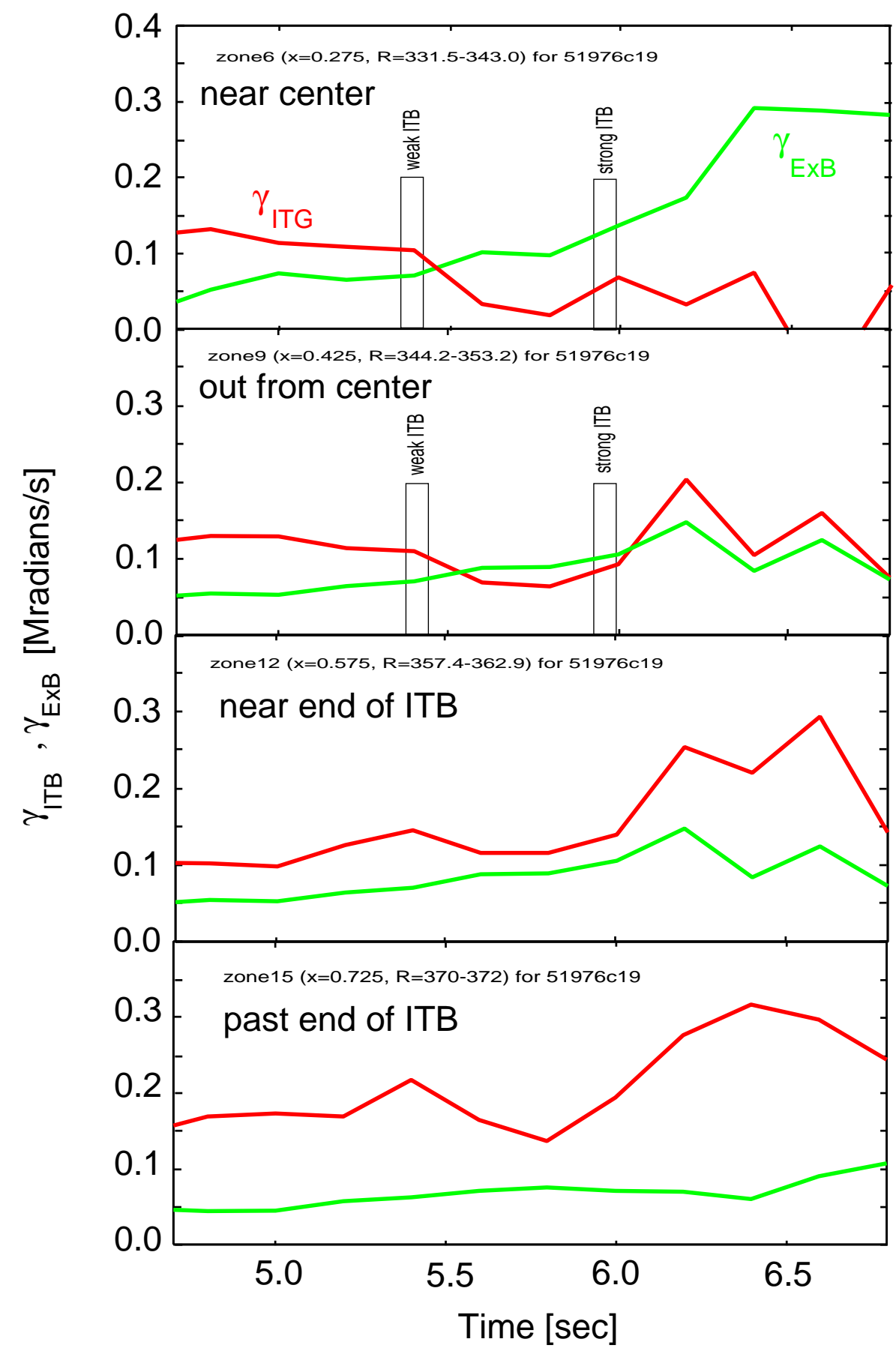

Figure 11 - Time evolutions at various zones. The rectangles indicate approximate occurrences of the break in the rate of increase of the local $T_{i}$ indicated in Fig. 2. The ITB's are very weak if they exist at all, for $x \geq 0.6$. 


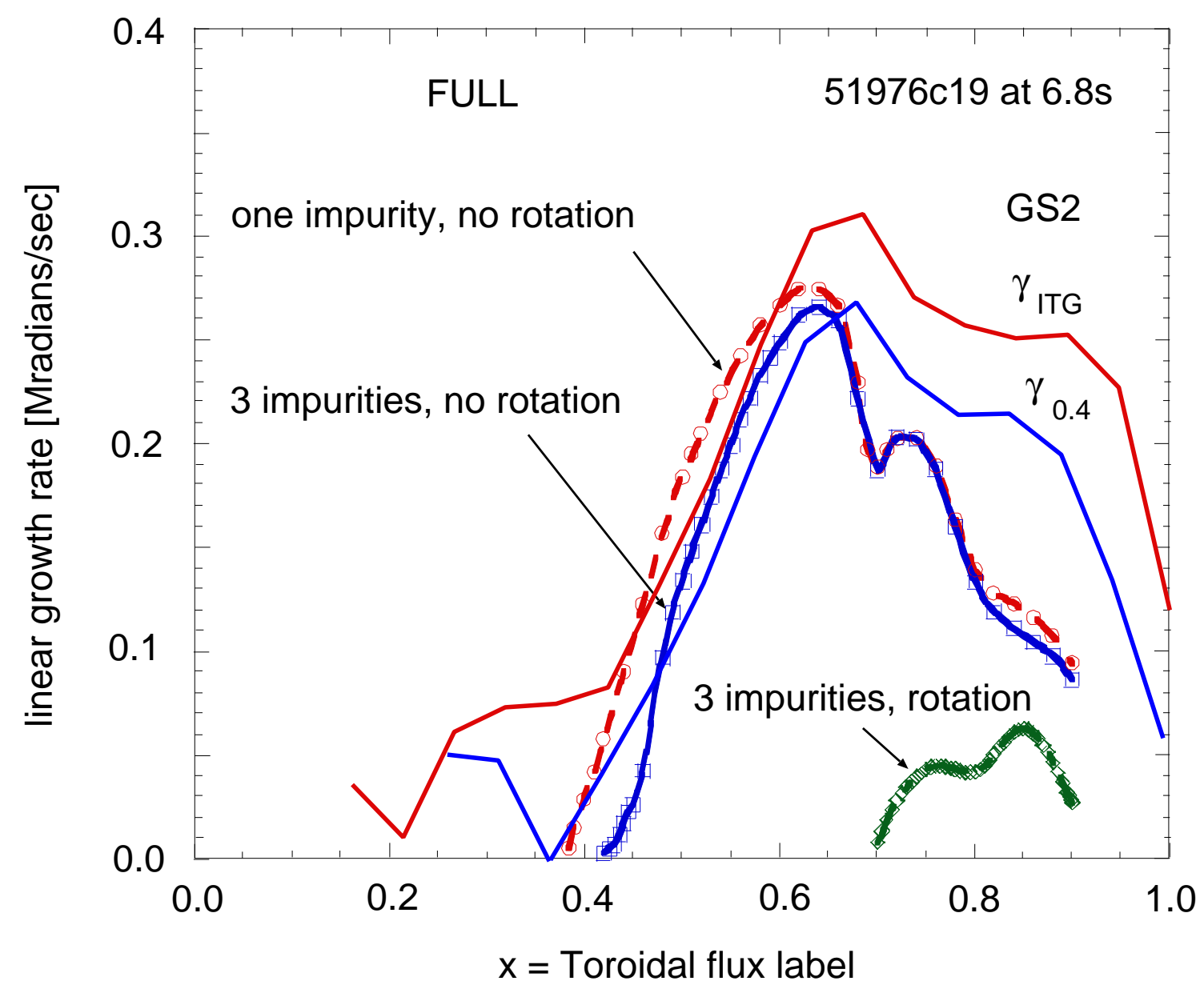

Figure 12 - Profiles of FULL and GS2 results at $6.8 \mathrm{~s}$, when the ITB has weakened or ceased to exist by $x=0.7$. Three profiles from FULL compare the growth rate calculated assuming a) a single average impurity species with no rotation and $k_{\theta} \rho_{i}=0.47$, b) three separate impurity species $\left(\mathrm{C}, \mathrm{Ne}\right.$, and $\mathrm{Ni}$ ) with no rotation and $k_{\theta} \rho_{i}=0.47$, and c) three separate impurity species, rotation, and $k_{\theta} \rho_{i}=0.68$. The GS2 results use the three impurity species, but do not include the rotation self-consistently. $\gamma_{I T G}$ is the GS2 result for $k_{\theta} \rho_{i}<1.0$, and $\gamma_{0.4}$ is the GS2 result for $k_{\theta} \rho_{i}=0.4$. The GS2 and FULL calculations started with the same TRANSP run, but used slightly different assumptions, as described in the text. 


\section{External Distribution}

Plasma Research Laboratory, Australian National University, Australia

Professor I.R. J ones, Flinders University, Australia

Professor J oão Canalle, Instituto de Fisica DEQ/IF - UERJ , Brazil

Mr. Gerson O. Ludwig, Instituto Nacional de Pesquisas, Brazil

Dr. P.H. Sakanaka, Instituto Fisica, Brazil

The Librarian, Culham Laboratory, England

Library, R61, Rutherford Appleton Laboratory, England

Mrs. S.A. Hutchinson, JET Library, England

Professor M.N. Bussac, Ecole Polytechnique, France

Librarian, Max-Planck-Institut für Plasmaphysik, Germany

J olan Moldvai, Reports Library, MTA KFKI-ATKI, Hungary

Dr. P. Kaw, Institute for Plasma Research, India

Ms. P.J . Pathak, Librarian, Insitute for Plasma Research, India

Ms. Clelia De Palo, Associazione EURATOM-ENEA, I taly

Dr. G. Grosso, Instituto di Fisica del Plasma, Italy

Librarian, Naka Fusion Research Establishment, J AERI, J apan

Library, Plasma Physics Laboratory, Kyoto University, J apan

Research Information Center, National Institute for Fusion Science, J apan

Dr. O. Mitarai, Kyushu Tokai University, J apan

Library, Academia Sinica, Institute of Plasma Physics, People's Republic of China

Shih-Tung Tsai, Institute of Physics, Chinese Academy of Sciences, People's Republic of China

Dr. S. Mirnov, TRINITI, Troitsk, Russian Federation, Russia

Dr. V.S. Strelkov, Kurchatov Institute, Russian Federation, Russia

Professor Peter Lukac, Katedra Fyziky Plazmy MFF UK, Mlynska dolina F-2, Komenskeho Univerzita, SK-842 15 Bratislava, Slovakia

Dr. G.S. Lee, Korea Basic Science Institute, South Korea

Mr. Dennis Bruggink, Fusion Library, University of Wisconsin, USA

Institute for Plasma Research, University of Maryland, USA

Librarian, Fusion Energy Division, Oak Ridge National Laboratory, USA

Librarian, Institute of Fusion Studies, University of Texas, USA

Librarian, Magnetic Fusion Program, Lawrence Livermore National Laboratory, USA

Library, General Atomics, USA

Plasma Physics Group, Fusion Energy Research Program, University of California at San Diego, USA

Plasma Physics Library, Columbia University, USA

Alkesh Punjabi, Center for Fusion Research and Training, Hampton University, USA

Dr. W.M. Stacey, Fusion Research Center, Georgia Institute of Technology, USA

Dr. J ohn Willis, U.S. Department of Energy, Office of Fusion Energy Sciences, USA

Mr. Paul H. Wright, Indianapolis, Indiana, USA 
The Princeton Plasma Physics Laboratory is operated by Princeton University under contract with the U.S. Department of Energy.

\author{
Information Services \\ Princeton Plasma Physics Laboratory \\ P.O. Box 451 \\ Princeton, NJ 08543
}

Phone: 609-243-2750

Fax: 609-243-2751

e-mail: pppl_info@pppl.gov

Internet Address: http://www.pppl.gov 